\title{
Another link between aortopathy and congenital anomaly?
}

\author{
Hiroo Takayama, MD, $\mathrm{PhD}$
}

See related article on pages 1586-92.

In the current study, Dr Dumfarth and colleagues ${ }^{1}$ from Yale University, a well-respected aortic surgery research group, summarized the findings of the aortic imaging studies in their aortic surgery database, focusing on the branching patterns of the aortic arch and head vessels. Their study cohort consisted of 556 patients who underwent thoracic aortic surgery. Anomalous branching patterns, including bovine arch, isolated left vertebral artery, and aberrant right subclavian artery, were found to be more common in these patients than in normal controls previously reported by others.

The clinical implications of this $\operatorname{article~}^{1}$ can be summarized as follows: First is simply its descriptive information on the prevalence of each abnormal branching pattern. The bovine arch, the most common branching anomaly of the arch, and its relationship with aortopathy has been reported in the past; however, publication of their work in the Journal will help to draw surgeons' attention to this previously underrecognized association. In addition, this study's finding of the isolated left vertebral artery has not been previously reported. Who knew the prevalence of isolated left vertebral artery is $6.3 \%$ among those who are undergoing aortic surgery! The second is the potential relationship between these arch anomalies and the development of aortopathy. Both of these findings could become integral components of patient management and the informed consent process.

That being said, the current study did not conclusively demonstrate a causal relationship between atypical arch branching variants and the aortic diseases. The methodological limitations precluded further investigations with

From the Department of Surgery, Columbia University Medical Center, New York, NY.

Disclosures: Author has nothing to disclose with regard to commercial support.

Received for publication Feb 17, 2015; accepted for publication Feb 20, 2015; available ahead of print April 1, 2015.

Address for reprints: Hiroo Takayama, MD, PhD, 177 Fort Washington Ave, New York, NY 10032 (E-mail: hirofu2@hotmail.com).

J Thorac Cardiovasc Surg 2015;149:1593-4

$0022-5223 / \$ 36.00$

Copyright (c) 2015 by The American Association for Thoracic Surgery

http://dx.doi.org/10.1016/j.jtcvs.2015.02.032 regard to the size before and at the development of aortic dissections and the growth rate of the aneurysms. Also, previously reported cohort studies were used as their controls, and this may have introduced biases. For instance, a significant fraction $(18 \%)$ of the "control" group had the arch anomaly. It would have been inter-

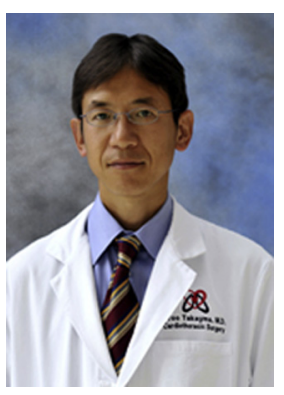
esting if the authors had access to the original data from these published series. However, these limitations do not decrease the importance of the present work, and it should trigger various future projects, such as hemodynamic, embryonic, and genetic investigation to further elucidate a causal association (just as it did with bicuspid aortic valves).

I congratulate and thank the authors for another excellent contribution from the Yale University aortic research group. Their landmark work on the natural history of the aortic aneurysm guides the management of patients worldwide, and their publications continue to advance the field of aortic surgery. ${ }^{2,3}$ Aortic diseases are one of the only disease entities for which cardiovascular surgeons remain "gatekeepers." For other entities, such as coronary artery disease, structural valvular diseases, and heart failure, our specialty mainly serves as a secondary or tertiary care provider. Although the lines between surgical and medical specialties are becoming blurred, it is important to understand and participate in patient management throughout the disease process to continue to play a major role within the "heart team." In this sense, our specialty should not focus solely on the technical aspects or short-term outcomes of the procedures, and the work from this group illustrates how our specialty can stay in the mainstream of cardiovascular medicine. Of no doubt, our colleagues are becoming more interested in this area through the work of the stent grafts.

\section{References}

1. Dumfarth J, Chou AS, Ziganshin BA, Rohan Bhandari R, Peterss S, Tranquilli $M$, et al. Atypical aortic arch branching variants: a novel marker for thoracic aortic disease. J Thorac Cardiovasc Surg. 2015;149: 1586-92.

2. Hiratzka LF, Bakris GL, Beckman JA, Bersin RM, Carr VF, Casey DE Jr et al. 2010 ACCF/AHA/AATS/ACR/ASA/SCA/SCAI/SIR/STS/SVM guidelines for the diagnosis and management of patients with Thoracic Aortic Disease: a report of the American College of Cardiology Foundation/American Heart Association Task Force on Practice Guidelines, American Association for Thoracic Surgery, American College of Radiology, American Stroke 
Association, Society of Cardiovascular Anesthesiologists, Society for Cardiovascular Angiography and Interventions, Society of Interventional Radiology, Society of Thoracic Surgeons, and Society for Vascular Medicine. Circulation. 2010;121:e266-369.
3. Svensson LG, Adams DH, Bonow RO, Kouchoukos NT, Miller DC, O'Gara PT, et al. Aortic valve and ascending aorta guidelines for management and quality measures. Ann Thorac Surg. 2013;95(6 Suppl): S1-66. 